\title{
Spotted around the web: Mislabeled 'autism traits,' cerebellum in autism, medicinal cannabis
}

\author{
BY JILL ADAMS, ANGIE VOYLES ASKHAM, LAURA DATTARO, NIKO MCCARTY
}

27 AUGUST 2021

WEEK OF AUGUST $23^{\text {RD }}$

\section{Research roundup}

- The Classroom Observation Scale, an autism screening tool developed in English for use by teachers, appears to translate well to Chinese-language settings. Autism

- A magnetic resonance imaging study confirms previous postmortem findings that autistic people tend to have altered brain microstructures. European Journal of Neuroscience

Altered morphology: Autistic people may have increased gray matter in some brain areas, such as the right orbitofrontal cortex.

- It is misleading to label difficulties in social communication as 'autism traits,' researchers argue, as there may be other reasons for the observed behavior. The American Journal of Psychiatry

- Pregnant women with a psychiatric diagnosis have an elevated chance of having a child with a neurodevelopmental condition such as autism; whether they take selective serotonin reuptake inhibitors, however, has no effect on those odds. Biological Psychiatry

- Heightened motor activity in toddlers appears to be an early sign of autism or attention deficit hyperactivity disorder. Journal of Child Psychology and Psychiatry

- Medicinal cannabis may help manage autism-related behaviors in children and make it possible to lower their doses of prescription psychotropic drugs. Child: Care, Health and 


\section{Spectrum | Autism Research News}

https://www.spectrumnews.org

\section{Development}

- Researchers continue to explore the cerebellum's role beyond motor control in cognition, behavior and development. A Spectrum explainer describes how the cerebellum may be involved in autism. Cellular and Molecular Life Sciences

- Infants later diagnosed with autism have atypical brain connectivity patterns by 9 months of age. Cerebral Cortex

- Mutations in the KIF2A gene, linked to drug-resistant epilepsy, cause behavioral changes and susceptibility to seizures in zebrafish. eNeuro

\section{Science and society}

- Despite laws that say employers cannot discriminate against workers with disabilities, such bias likely contributes to the high rates of unemployment and underemployment among people on the spectrum. Medical News Today

- Autistic journalist Matthew Rosza talked to autistic author Eric Garcia about his new book, "We're Not Broken." Salon

- David Sabatini, who first described mTOR - a protein involved in cellular growth and linked to autism - has been fired from Howard Hughes Medical Institute and has resigned from the Whitehead Institute because of sexual harassment charges. Spectrum profiled Sabatini and his brother in 2018 . Science 